\title{
浅谈初中音乐课堂教学中培养歌唱能力的策略
}

\author{
秦雨虹 \\ 北京师范大学江津附属学校初中部 \\ DOI:10.32629/er.v2i3.1732
}

[摘 要] 新课改的发布以及应用已经不断深入到当今的教育教学过程中, 在当今教学环境下, 初中生更多具备叛逆心理,使得 音乐课堂的教学会受到一定阻碍, 初中生不能够有效掌握音乐知识技能,无法良好的培养他们唱歌能力, 甚至还有一些专注文 化课的学生对音乐课的不重视, 使得他们的唱歌能力无法得到提升。唱歌教学是初中音乐的重要内容, 在学习过程中, 老师要加 强对学生的兴趣培养, 这样才能提高他们的求知欲。我们根据实际的初中音乐教学情况, 对初中音乐教学中培养学生唱歌能力 提出一定的解决措施。

[关键词] 初中音乐; 唱歌能力; 音乐教学

在素质教学的大前提下, 我们要求初中音乐老师要提高 学生的学习兴趣, 培养和加强他们对音乐教学的理解和熟悉, 掌握正确的发音方法, 这样才能进一步培养思想思维, 教师 可以创新多元化教学模式, 加强学生对于发音规律的掌握, 提高他们的唱歌能力。歌曲是通过词和话语的相结合来抒发 情感的, 是一种能够良好表达人内心情感的艺术形式, 真正 的好歌能够给人带来良好的审美感觉, 而让初中生唱好歌也 是音乐教学的一项重要内容。我们通过歌曲对学生进行德育 教育, 进一步提高他们的审美情趣。但同时初中音乐教学又 很不容易进行, 如何将枯燥的歌唱技巧转换的生动灵活, 让 学生们感受到音乐的魅力, 等等, 这些都是需要初中音乐教 师急需探索和解决的问题。

\section{1 培养学生学习兴趣是前提}

任何一种事情的完成都需要兴趣的培养和提升, 对一件 事充满兴趣是能力提升的基础和前提。而对于初中生来说, 音乐老师要加强对学生的音乐兴趣培养, 教师在展示歌曲的 过程中, 尽量完整的表现其艺术形象, 让学生能够充满求知 欲, 这样才能够进一步探索音乐内部的鬼力。初中生的年龄 阶段大多具有叛逆性, 而对于音乐的了解也是未知的, 我们 要抓住他们的年龄特点和生理规律, 让他们觉得音乐是具有 趣味的, 激发学习兴趣。但同时我们也要注意, 不要采取强制 性措施, 否则会扼杀学生的兴趣。对于初中音乐教师来说, 授课过程中不仅仅要培养相关技能技巧, 教学的目的也并不 是造就一个音乐家, 其根本在于通过音乐艺术的鬼米力来培养 他们学习兴趣, 使他们能够亲近艺术了解艺术。在生活中, 很多人大多会由于一首歌、一首曲从而慢慢喜欢上音乐, 音 乐教育的目的也不是要培养一个技能高超的人才, 我们要做 音乐的听众, 从心底里慢慢了解音乐对其产生兴趣, 这样才 能更好的进行日后的音乐唱歌能力培养。

比如, 在音乐课堂上我们可以采取互动的方式, 教师带 领学生们充分享受音乐, 可以设置一些特定动作在音乐伴奏 下进行舞动, 通过音乐当中美丽的画面和动听乐曲带领学生 去听去看, 从而激发学生的听觉视觉, 让学生们能够直观地
感受到音乐鬼力, 同时还能进一步促进他们的思想能力, 不 仅仅只是单纯的听讲, 还动脑筋想从而吸引他们的注意力。 这种模式下能够营造良好的音乐氛围, 让学生们能够深刻地 感受音乐所散发的情感, 同时也缩短, 师生之间距离, 使得音 乐教学能够更好的走下去。

\section{2 掌握正确的发声方法是关键}

对于音乐教学掌握正确的发声方法是很有必要的, 如果 老师只追求上课数量而不注重质量, 学生不能掌握正确的练 习方法, 不仅会影响学生对音乐的学习兴趣, 甚至还会损害 嗓子等器官。一个人的嗓子就像一件乐器, 我们只有运用正 确科学的发生方法才能演绎出美妙的声音。了解发生方法是 学习音乐的关键, 我们首先要了解其内部结构, 发生时需要 用到身体的哪些部位, 而这些部位的作用通常又是什么, 这 些都是我们首先需要了解的。音乐还分很多唱法, 有民族歌 的唱法还有美声的唱法, 不同唱法运用的发声方法也有所不 同, 我们要根据个人喜好来进行学习, 不能仅仅依靠模仿胡 乱发出声音, 这样不仅影响美感, 也会对身体造成一定损害。

教师在课堂过程中也要由其观察每一个学生的发声方 法, 可以带领学生一起训练, 从而对学生的错误发声进行及 时的纠正和更改, 也可以通过视频图像等方式让学生清楚的 了解发声的部位以及发声时该部位的变化情况, 让学生们直 观的感受远远比教师进行单纯的口述效果更高。同时教师也 要在课上积极促进学生进行尝试, 要敢唱想唱, 这样才能发 现问题所在, 课下也要督促初中生进行训练, 及时的练习才 能巩固。

\section{3 培养音乐欣赏能力和思维能力}

3.1 培养音乐欣赏能力

对初中生进行音乐教学能够综合发展学生各方面能力, 而培养学生对音乐的欣赏能力很重要, 只有具备对音乐的欣 赏能力, 才能感受到音乐散发的魅力, 从而对内心情感造成 一定影响, 产生一定的积极作用。教师除了进行教材上规定 音乐曲目的教学之外, 还可以让学生欣赏更多的曲目, 这样 能够拓宽学生的见识, 培养学生综合听力的练习。教师还要 
根据实际情况出发, 采用生动形象的教学模式, 找到一种适 应课堂以及自己学生的教学, 这样才能提高教学质量, 进一 步培养学生的音乐欣赏能力。在很多情况下课堂不仅仅是老 师的课堂, 也需要同学们的发言, 通过互动将课堂生动活泼 的进行下去, 教师在传授音乐技能技巧的同时可以讲述对应 音乐的故事, 让学生也发表看法, 这样能够加强学生对音乐 的欣赏能力, 也为今后的音乐赏析打下基础。

\section{2 加强思维想象能力}

文字是人们用肉眼看到的, 而音乐是人们用耳朵听到的, 两者所感知的器官不同, 进行的思维联想也有很大的不同之 处。相比之下, 文字能够清楚明确的表达它所讲述的内容以 及思维模式, 而音乐是利用人们的感知力, 通过对音乐的不 同理解, 从而产生丰富的想象力和联想, 不同人对音乐的见 解不同所想象出来的事物也各不相同。我们加强对音乐的教 学能够进一步培养和增强学生的想象力, 通过视觉和听觉来 对音乐进行赏析, 提高初中生的听觉和视觉能力综合应用。 在学习过程中, 学生会跟随音乐的紧张而紧张、放松而放松, 很大程度上能够促进学生思维和情感的活跃度, 有助于对他 们的思维能力培养。教师在教学过程中可以多为学生播放音 乐, 可以播放一些情绪丰富的音乐, 从而触动学生的内心情 感增强他们的感知力。在这期间还可以穿插不同类型风格的 曲目, 加强学生的思维转换, 培养他们的联想和想象能力, 这 对今后的发展有很大帮助。

\section{4 探索多元化教学模式}

音乐教学本就不同于其他文化课的教学, 它有很强的感 染力, 而且培养学生的唱歌能力时大多需要学生自己开口唱, 如果只是单纯的传统教学, 很容易使学生丧失学习兴趣, 不 利于学生对音乐的唱歌能力学习。这就需要教师不断创新多 元化教学模式, 传授不同风格的曲目时采用不同的教学方法, 加强音乐教学的规律性, 这样才能提高学生的学习效率。音 乐的教学不是死板乏味的, 它需要教师根据每一个学生的不 同情况来进行课程设定, 做到因材施教。在传统的音乐教学 方法中, 教师往往只关注唱歌技巧以及音乐技能的训练, 从 而忽视了音乐作为一门艺术的完整性。在音乐课堂中, 我们 要让学生充分感受到音乐所散发的情感, 而学生在唱歌时也 需要从内心出发, 真正感受音乐的魅力。教师在歌唱教学中,
要通过正确的发生方法来表达自己的情感, 从而进行音乐歌 唱, 争取能够做到感染学生。在课堂中, 我们也要采用不同形 式的表现方式, 可以通过不同乐器来帮助学生们演奏音乐, 降低学生唱歌的困难点, 让学生能够敢唱想唱, 这样他们才 会慢慢的深入了解音乐的魅力以及歌唱时的享受。

\section{5 掌握音乐教学中特定规律}

我们都知道, 没有哪两首歌是一模一样的旋律, 每一首 歌曲都有其独特韵味, 而音乐教师要做到的, 就是在授课过 程中让学生们能够感受其独特韵味的存在, 这样能够让学生 充分了解该歌曲表达的情感, 从而提高歌唱能力。在这一过 程中就要求教师在授课之前要充分学习歌曲, 这当中包括创 作背景、情感元素、歌词内容, 甚至还需要了解作家的相关 经历等等, 只有充分了解了教师才能在课堂上为学生进行良 好示范, 这样的课堂气氛是生动亲切的。同时还能传授给学 生正确的歌唱技巧, 帮助学生快速掌握歌曲特征旋律以及其 特定规律, 这种情况下, 能够有效提高学生的歌唱能力, 从而 起到事半功倍的效果。对于初中生来说, 在进行课下的训练 时, 我们赏析一首曲目, 首先就要了解其内部情感和特定规 律, 只有真正了解音乐所表达的内涵, 才能在歌唱过程中表 达出想要让人们听到的故事, 这对于学生的思维能力也有很 大帮助。

\section{6 结束语}

在当代教育的大背景下, 加强初中生的音乐歌唱能力培 养是很关键的, 歌唱教学不仅仅是培养学生审美能力的过程, 同时也是营造美和发现美的过程。音乐教师在教学过程中要 总结探究教学方法、创新多元化教学模式, 加强理论联系实 际, 不断提高自身的专业知识水平, 这样才能带给学生一个 充满情感的音乐气氛, 加强学生的学习兴趣。

\section{[参考文献]}

[1]崔晓娟.初中音乐课堂引入情感教育的方式及意义 探索[J].北极光,2019(01):58.

[2] 李建良.初中音乐课堂教学中培养歌唱能力的策略 [J].黄河之声,2018(23):36.

[3]谭玉冰.初中音乐课堂教学中培养歌唱能力的有效策 略和方法[J].艺术评鉴,2018(10):36-37. 